\title{
La lectura académica en entornos virtuales. A propósito del aislamiento social preventivo y obligatorio (ASPO)
}

\author{
Amelia María Zerillo \\ Universidad Nacional de La Matanza. \\ amariaz2008@gmail.com \\ ORCID: https://orcid.org/0000-0001-9238-4571
}

Ana M. Bidiña

Universidad Nacional de La Matanza.

ana.bidina@gmail.com

ORCID: https://orcid.org/0000-0001-9238-4571

M. Fernanda Espelta

Universidad Nacional de La Matanza.

fernandaespelta@gmail.com

ORCID: https://orcid.org/0000-0001-9238-4571

Nora A. Carra

Universidad de La Matanza

noracarra@gmail.com

ORCID: https://orcid.org/0000-0002-9779-6089

Fecha de finalización: 30 de noviembre de 2020. Recibido: 30 de agosto de 2021

Aceptado: 28 de octubre de 2021 .

DOI: https://doi.org/10.26422/aucom.2021.1002.zer

\section{Resumen}

La lectura y la escritura en la universidad constituyen procesos que requieren ser enseñados explícitamente en la educación superior. Su enseñanza es una responsabilidad de la comunidad académica que debe propender a la transmisión de la cultura letrada aún en las situaciones más adversas. El Aislamiento Social Preventivo y Obligatorio instaurado en 2020, con sus entornos virtuales y multimodales, puso a prueba las prácticas letradas tradicionales en soporte papel y las competencias de la comunidad académica para leer y escribir en pantalla. Este artículo da cuenta de la investigación realizada en torno a la lectura en la Universidad Nacional de La Matanza, una institución que privilegia la equidad y la calidad en educación y que cuenta con una numerosa población estudiantil de recursos económicos medios y escasos. La indagación se realizó sobre la base de encuestas no probabilísticas analizadas cuantitativa y cualitativamente, sobre todo en aquellos casos que ameritaban una descripción más profunda y un estudio más específico. Los resultados muestran diferencias en el interior de las disciplinas e interesantes beneficios de la virtualidad. 
Amelia María Zerillo, M. Fernanda Espelta, Nora A. Carra

La lectura académica en entornos virtuales. A propósito del aislamiento social preventivo y obligatorio (ASPO)

Palabras clave: alfabetización, alfabetización académica, prácticas letradas, lectura académica, multimodalidad.

\title{
Reading in virtual classrooms: on preventive and obligatory social isolation
}

\begin{abstract}
Reading and writing at the university level are skills that should be taught in higher education. Teaching these skills is the responsibility of the academic community, tasked with cultivating an appreciation for literary or written culture even in the most adverse conditions. In Argentina, during 2020, the national government's decree of Preventive and Obligatory Social Isolation (also known by its Spanish acronym, ASPO) meant faculty and students had to adjust to virtual and multimodal environments. This put traditional university practices - tethered to physical paper - to the test. And it forced the academic community to prove its competence in writing and reading on a screen. The following article regards an investigation on the act of reading in an academic context. It was carried out at the National University of La Matanza, an institution focused on social justice and providing a quality education, whose sizable student body mostly comes from working-class families. The investigation was based on non-probability surveys, analysed both quantitatively and qualitatively, especially when the situation called for a more thorough, specific study. Our results show the differences between academic fields and reveal some of the interesting benefits of virtual classrooms.
\end{abstract}

Keywords: literacy, academic literacy, written practices, academic reading, multimodality.

\section{Leitura academica em ambientes virtuais. A propóstio do isolamento social preventivo e obrigatório}

\section{Resumo}

Ler e escrever na universidade são processos que precisam ser explicitamente ensinados no ensino superior. Seu ensino é uma responsabilidade da comunidade acadêmica que deve tender à transmissão da cultura letrada mesmo nas situações mais adversas. O "Isolamento Social Preventivo e Obrigatório" em 2020, decretado no contexto da pandemia COVID-19, levou a ambientes virtuais e multimodais, testando assim as práticas letradas tradicionais baseadas em papel e as habilidades da comunidade acadêmica para ler e escrever no computador.

O Isolamento Social Preventivo e Obrigatório instituído em 2020, com os seus ambientes virtuais e multimodais, pôs à prova as práticas jurídicas tradicionais no papel e as competências da comunidade académica para ler e escrever na tela. Este artigo conta a pesquisa realizada em torno da alfabetização na Universidade Nacional de La Matanza, uma universidade pública argentina que privilegia a equidade e a qualidade na educação ademais de ter uma grande população estudantil com recursos econômicos de meios a baixos, que possui cinco departamentos e o ditado de vinte e seis graduações e graduação. A pesquisa foi realizada com base em dados obtidos a partir de inquéritos não probabilísticos, analisados quantitativa e qualitativamente, em especial para os casos que justificavam uma descrição mais profunda e um estudo mais específico. Os resultados mostram diferenças da disciplina a disciplina, e interessantes benefícios da virtualidade.

Palavras chave: alfabetização acadêmica, alfabetização, leitura acadêmica, cultura letrada, multimodalidade. 


\section{Austral@municación \\ Volumen 10, número 2 (Diciembre de 2021): 351-373 ISSN (I) 2313-9129. ISSN (E) 2313-9137}

\section{Introducción}

La relación entre lenguaje y pensamiento viene desarrollándose desde la antigüedad clásica. Sus mutuas implicancias han dado lugar a numerosas polémicas (Sapir, 1954; Whorf, 1956) que no vamos a desarrollar aquí, pero es necesario mencionar que esa discusión ha servido para pensar la relación estrecha que existe entre lenguaje y aprendizaje en general. Psicólogos cognitivos (Bruner, 1984), sociólogos (Berstein, 1965) y lingüistas (Halliday, 2004) han señalado que la experiencia y el conocimiento se socioconstruyen y sociocomunican a través del lenguaje en distintos espacios de interacción social (Vygotsky, 1978); el aula es uno de ellos. En consecuencia, el lenguaje ocupa un lugar central en el aprendizaje de las ciencias en la escuela y en la universidad, espacios en los que aprender ciencia significa, entre otras operaciones, aprender a hablar y a escribir sobre ciencia con su lenguaje y configuraciones específicas.

En este marco, la ciencia es un proceso social, enseñado, aprendido y realizado por comunidades sociales que manejan un lenguaje común: el de la ciencia que estén practicando, enseñando o aprendiendo (Lemke, 1997). Estudiantes, docentes y científicos deben manejar el mismo lenguaje y conocer las herramientas que hacen de la ciencia un discurso que se vuelve, en muchos casos, escritura tanto para aprenderla (estudiantes) como para producirla (científicos) y comunicarla (científicos y docentes).

Esta búsqueda del lenguaje común y el manejo de la retórica de la disciplina requieren de un entrenamiento docente (Bazerman et al., 2005) que, entendemos, no debe descuidar la enseñanza de la lengua de base (Martin y Rose, 2012, p. 40) que permita: a) hacerles entender a los estudiantes cómo funciona la lengua; $y$ b) desarrollar un metalenguaje que les permita hablar de ella, actividad metarreflexiva absolutamente necesaria para generar autonomía en ellos. La idea es lograr entender el lenguaje de la ciencia, los distintos procedimientos de análisis y descripción de los distintos objetos, las conceptualizaciones, nominalizaciones, reformulaciones, metodologías y abrir el acceso a los recursos semióticos de cada disciplina (Martin y Rose, 2012, p. 318).

En síntesis, la lectoescritura de la ciencia es una práctica que debe enseñarse y que debe acompañar al estudiante a lo largo de su formación de grado no solo ni principalmente para subsanar carencias provenientes de niveles previos del sistema, sino también como actividad formativa específica del nivel universitario, para permitir el acceso a una comunidad discursiva especializada en tanto y en cuanto los estudiantes nunca han formado parte de ella y no tienen esa experiencia (Carlino, 2004). La lectoescritura de la ciencia se da generalmente a través de la mediación de los académicos, de los especialistas en la disciplina en su carácter de docentes, a través de materiales que se denominan "científico-académicos" en función de su espacio de circulación y que aquí hemos denominado simplemente "académicos". 
Amelia María Zerillo, M. Fernanda Espelta, Nora A. Carra

La lectura académica en entornos virtuales. A propósito del aislamiento social preventivo y obligatorio (ASPO)

Desde una mirada más institucional, la lectura y la escritura son dos prácticas esenciales en la configuración de egresados universitarios integrales, reflexivos, críticos y con conciencia social (Ley 25573 de 2002). Es a través de los intercambios mediados por la cultura escrita que los sujetos construyen su identidad social como profesionales, investigadores y autores (Tolchinsky, 2013). Los psicólogos, por ejemplo, utilizan un vocabulario, una organización del discurso y unos giros idiomáticos que los diferencian de los abogados. Esto se debe a que las comunidades disciplinares son comunidades discursivas. Por medio de los intercambios verbales, orales y escritos -recién llegados y veteranos- van integrándose y perfilándose en la comunidad a través de la lectura y la escritura. Los estudiantes de psicología van asumiendo maneras de comunicarse propias de los psicólogos; los estudiantes de derecho, maneras propias de los abogados. En esta interacción, leer e interpretar adecuadamente las comunicaciones escritas es vital y puede determinar el éxito profesional. También es esencial para la integración de los nuevos miembros académicos en las respectivas comunidades discursivas y en la sociedad en general (Bazerman et al., 2005). Según estos conceptos, queda claro que no existe disciplina universitaria que pueda prescindir de la comunicación escrita ni de las competencias que la sustentan y que desarrollar esas competencias son dos objetivos cruciales de toda comunidad académica.

El Aislamiento Social Preventivo y Obligatorio (ASPO) implementado en 2020 puso a prueba la educación y las prácticas letradas vinculadas a los documentos escritos. El encierro y los recursos tecnológicos provistos por las universidades hicieron de la ocasión el momento propicio para investigar tanto el grado de presencia e importancia de esas modalidades tradicionales en los procesos de enseñanza y aprendizaje como la incidencia de las nuevas tecnologías de la información y la comunicación (TIC) en el mejoramiento de los hábitos específicos de la cultura escrita y el compromiso de los docentes de las distintas disciplinas en el desarrollo de estos últimos.

Dada la oportunidad, nuestro equipo de investigación se propuso examinar las prácticas de lectura y escritura desarrolladas en los entornos virtuales desde el punto de vista de los estudiantes y de los docentes, además de las representaciones que tienen sobre la importancia de la lectura los distintos espacios disciplinares. Es decir, las creencias que tienen sobre la función epistémica de la lectura. En este artículo, presentamos específicamente los resultados obtenidos en relación con la lectura académica.

Respecto a la lectura en particular, las investigaciones cognitivas y lingüísticas consideran que tanto la lectura como la escritura son procesos activos de construcción de significados para los que se requieren competencias diversas (Parodi, 1999). En el caso de la lectura, durante ese proceso de acciones intra y extratextuales, el lector examina los paratextos para contextualizar la obra, analiza sus destinatarios, lee el texto, vincula 


\section{Austral @municación \\ Volumen 10, número 2 (Diciembre de 2021): 351-373 ISSN (I) 2313-9129. ISSN (E) 2313-9137}

ambas informaciones y construye sentidos provisorios que serán reemplazados por uno más estable y final.

La secuencialidad lineal dominante en la lectura de los textos tradicionales es bastante conocida (más allá de los experimentos de vanguardia y de la experiencia con Rayuela de Julio Cortázar). En la era y cultura digital, el movimiento psicofísico de comprensión y producción, ligado ahora al formato electrónico digital, ha sufrido una serie de alteraciones que delimitan la frontera entre el escenario gutenberiano y el digital (Piscitelli, 2010).

En el escenario digital, el lector/escritor es usuario y navega/explora los contenidos del hipertexto a través de la pantalla en un recorrido absolutamente personal. Allí dispone de cine, radio, televisión y tiene acceso a todos los periódicos digitales; mientras lee o escribe, puede visitar museos, presenciar un concierto, acceder a mundos virtuales, recorrer bibliotecas y acceder a la gran biblioteca universal que es la World Wide Web (Lamarca Lapuente, 2009). En esos recorridos, el lector y el escritor van y vienen interrumpiendo la modalidad canónica de lectura, y el lector poco entrenado frecuentemente se pierde.

En otras palabras, en el escenario digital, el paradigma secuencial-lineal del proceso de lectoescritura tradicional es sustituido por la exploración/navegación del hipertexto y su océano de posibilidades. En la lectura analógica o gutenberiana, la lectura es más lineal y controlada. Los procesos inferenciales parecen más propicios y la lectura crítica también.

Gracias a los recursos tecnológicos, el lector más entrenado puede leer, compartir lecturas, conversar sobre ellas y crear rápidamente grupos de consulta y de trabajo colaborativo sin dejar de estimar que, para hacer un trabajo más reflexivo, en el caso de algunos géneros puede necesitar la lectura en papel (García Canclini et al., 2015).

Los lectores menos avezados encuentran dificultades en estos movimientos. Para ellos, los investigadores siguen señalando la necesidad de una didáctica de la lectura en pantalla que permita redefinir las estrategias que faciliten la comprensión profunda, la apropiación conceptual, el trabajo crítico y la construcción de nuevos conocimientos (Gómez, 2011), para así adentrarse en la lectura multimodal.

Partiendo de diferentes teorías lingüísticas y semióticas, Jewitt y Kress (2003) definen "modo" como un conjunto organizado y regularizado de recursos para significar y dar sentido, entre los que se incluyen la imagen, la mirada, el gesto, el movimiento, la música, el habla y los efectos de sonido. Así, los textos construyen significados no solo a partir del sistema verbal, sino también de los recursos provenientes de otros sistemas (tales como imágenes, sonidos, movimientos, etc.). Es necesario reconocer la naturaleza completamente multimodal de todo texto y ello implica una reconfiguración disciplinar a nivel epistemológico acerca de cómo se aborda el estudio de los textos. 
Amelia María Zerillo, M. Fernanda Espelta, Nora A. Carra

La lectura académica en entornos virtuales. A propósito del aislamiento social preventivo y obligatorio (ASPO)

Respecto a la enseñanza, González García (2013) describe una nueva alfabetización que ve en las imágenes, los gestos, la música, los movimientos, la animación y otros modos de representación, formas diferentes de plasmar y acceder al conocimiento. Las nuevas alfabetizaciones buscan aprovechar las características multimodales y flexibles que proveen los hipermedios para generar habilidades de pensamiento, fomentar aprendizaje, estimular la capacidad del estudiante para formular preguntas críticas. La incorporación de las TIC en los procesos de alfabetización desde una perspectiva multimodal posibilita nuevas formas de presentar la información, que exigen del sujeto lector nuevas habilidades para acceder a la información (Jewitt, 2009) y una renovación de los procesos pedagógicos y las estrategias didácticas del docente.

En cuanto a estos usos, algunos autores diferencian entre usuarios nativos e inmigrantes (Prensky, 2010) y otros prefieren el uso de otros términos. En esta investigación, a los efectos de que los consultados nos comprendieran con claridad sin necesidad de ir a consultar la teoría, preferimos hablar de "usuarios experimentados", "experimentantes", de usuarios que buscan apropiarse de las nuevas prácticas y de usuarios que se vieron presionados a hacerlo.

\section{Método}

El universo de análisis de esta investigación corresponde a la Universidad Nacional de La Matanza (en adelante, UNLaM). Esta institución fue creada en la década del 90 como parte de la política de expansión de la educación superior en el conurbano bonaerense -uno de los distritos educativos más grandes de la Argentina por su extensión y población (De Sena, 2020)- ${ }^{1}$ con el objetivo de promover el acceso y la permanencia de sectores sociales que antes estaban excluidos de este nivel educativo por distintas razones. Desde el punto de vista institucional, la UNLaM, del mismo modo que las restantes universidades, tuvo la posibilidad de implementar una política explícita de ingreso universitario que garantizara democráticamente el acceso al conocimiento. Así, frente a los modelos que van del ingreso irrestricto al ingreso altamente selectivo, la UNLaM optó por un modelo que han llamado de "ingreso responsable", que compromete tanto a los aspirantes que desean estudiar como a las instituciones que no pueden desconocer las dificultades que presentan las nuevas poblaciones de estudiantes a los efectos de reducir la tensión entre equidad y calidad educativa. Este compromiso se extiende a los distintos actores que intervienen en la formación de grado y al currículo de las diferentes materias de cada una de las carreras. Caracteriza a la UNLaM el hecho de ser una universidad de masas, con aulas muy pobladas, alum-

\footnotetext{
La Matanza tiene el distrito de mayor superficie (325,71 kilómetros cuadrados) y 1777530 habitantes, según el Instituto Nacional de Estadísticas y Censos (2010), y una proyección de 2281194 para 2020. Le sigue Lomas de Zamora, con 648312 (De Sena, 2020).
} 


\section{Austral Comunicación \\ Volumen 10, número 2 (Diciembre de 2021): 351-373 ISSN (I) 2313-9129. ISSN (E) 2313-9137}

nos que en su mayoría son universitarios de primera generación y trabajadores con medianos o escasos recursos. Su plantel docente está conformado por profesionales formados en distintas universidades y también por egresados de la propia universidad.

Para indagar las prácticas en entornos virtuales, se realizaron encuestas no probabilísticas a estudiantes y docentes de los distintos departamentos y áreas académicas de la UNLaM sobre la base de dos formularios autoadministrados y en línea (Microsoft Forms). La encuesta incluía preguntas cerradas de opciones múltiples y otras abiertas que les permitía opinar sobre la experiencia vivida en entornos virtuales y los nuevos modos de leer y escribir. La distribución se realizó mediante la técnica de "bola de nieve”. El diseño de la encuesta presentó preguntas de opción múltiple y otras de respuesta abierta que buscaban relevar información de tipo cualitativo. Para el análisis de los datos, se combinó el análisis cuantitativo con el análisis discursivo de los enunciados de los informantes en busca de representaciones sociales sobre las prácticas investigadas.

Respondieron la encuesta 2066 estudiantes $^{2}$ y 246 docentes. En este artículo nos centramos en las encuestas realizadas a los alumnos y, a los efectos de la verificación e interpretación de los datos, los hemos cruzado con las respuestas correspondientes a las de los docentes. La mayoría de los estudiantes que respondieron fueron mujeres y no solo habían realizado el curso de ingreso a la UNLaM, sino que también tenían cierta experiencia en la Universidad (el 56\% había cursado más de 8 materias) y pertenecían a una edad (entre 20-30 años) que lleva a considerarlos nativos digitales. El área disciplinar más representada por quienes accedieron a la encuesta fue la correspondiente a Ciencias de la Salud, le siguieron Ciencias Sociales, Ciencias Humanas y Ciencias de la Educación; las menos representadas fueron Ciencias Tecnológicas y Exactas y Ciencias Naturales. Con un nivel medio se destacaron Ciencias Jurídicas y Ciencias Económicas.

El entorno virtual de trabajo de la UNLaM se denomina MIeL (Materias Interactivas en Línea) y es -como en la mayoría de los casos- un simulacro de aula en el que estudiantes y docentes se encuentran para interactuar a distancia (no físicamente) durante el proceso pedagógico. Presenta herramientas de comunicación sincrónica: foros, ${ }^{3}$ videoconferencias vía Teams; y asincrónica: correo electrónico, videos, foros y herramientas de práctica y evaluación.

\footnotetext{
En este artículo usamos el masculino genérico. A menos que se mencione "estudiantes hombres" o "estudiantes mujeres", el genérico masculino o el neutro está haciendo alusión a ambos géneros en este documento. Lo mismo sucede con "los docentes" y "los alumnos". Usamos también la distinción genérica las/los estudiantes como variante de visibilización del género femenino. Pero a los efectos de no ser redundantes, alternamos entre las opciones que acabamos de delimitar.

3 Los foros de MIeL tienen las características de los chats, reúnen aspectos de la comunicación oral y escrita y pueden desarrollarse como una comunicación en presencia o de carácter diferido.
} 
Amelia María Zerillo, M. Fernanda Espelta, Nora A. Carra

La lectura académica en entornos virtuales. A propósito del aislamiento social preventivo y obligatorio (ASPO)

\section{Resultados}

Para comenzar, con respecto al uso de los entornos virtuales y la tecnología, el relevamiento de las encuestas mostró que el $32 \%$ de los estudiantes se sentía un sujeto que buscaba apropiarse de las nuevas prácticas, es decir, la lectura de textos digitales, las clases vía foro, la interacción con los compañeros en esos espacios y la comunicación virtual; y el 31\% se sintió presionado por las circunstancias. El 19\% se sintió experimentante y solo el $18 \%$ se reconoció experimentado.

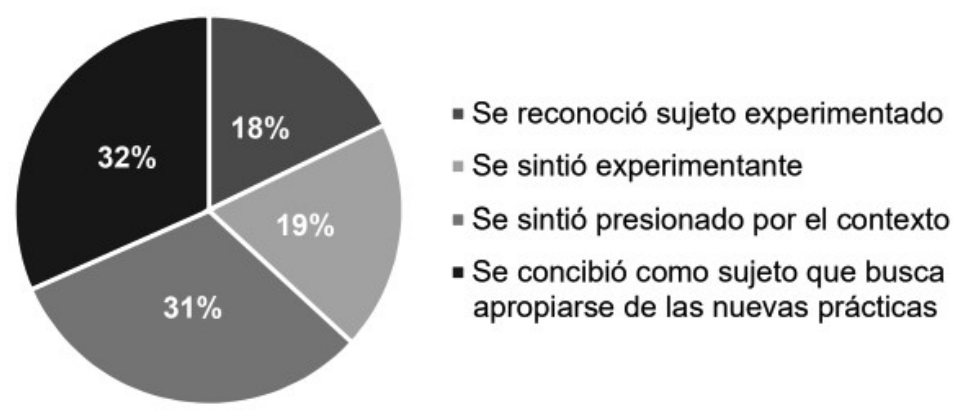

Figura 1. Subjetividad y nuevas tecnologías. (Fuente: elaboración propia).

Es decir que, según los datos relevados, la mayoría de los estudiantes contradicen esa creencia del mundo adulto que sostiene que internet y las nuevas tecnologías pertenecen al mundo joven y que, en esos espacios, ellos deberían moverse con mayor comodidad que los docentes.

Respecto al grado de presencia de documentos escritos en las clases, actividades y materiales bibliográficos, los estudiantes manifestaron notables diferencias. Un primer grupo afirmó que los docentes se manejaron con documentos escritos en un $61 \%$; un segundo grupo, que emplearon materiales escritos entre el $26 \%$ y $60 \%$; y un último grupo, que se usaron en menos de un $25 \%$ documentos escritos. Estos datos fueron confirmados por los docentes de las carreras más discursivas, que reconocieron haber empleado en mayor proporción documentos escritos para sus clases y, sobre todo, para las actividades y correcciones. Del dato se infiere que los materiales restantes tuvieron otros formatos: audios, videoconferencias o textos con imágenes tipo Power Point. Se deduce también que la variable disciplinar pudo tener incidencias importantes en los recursos utilizados por los docentes en el proceso pedagógico desarrollado.

El 48\% accedió a sus clases desde notebooks; el 32\%, desde computadoras; el 16\%, desde celular; un $2 \%$ usó tablet y otro $2 \%$ manifestó fotocopiar sus clases. Entre quienes tuvieron videoconferencias, el 66,67\% subrayó la necesidad de poner por escrito lo aprendido y, aparentemente, lo hizo. 
Austral Comunicación

Volumen 10, número 2 (Diciembre de 2021): 351-373 ISSN (I) 2313-9129. ISSN (E) 2313-9137

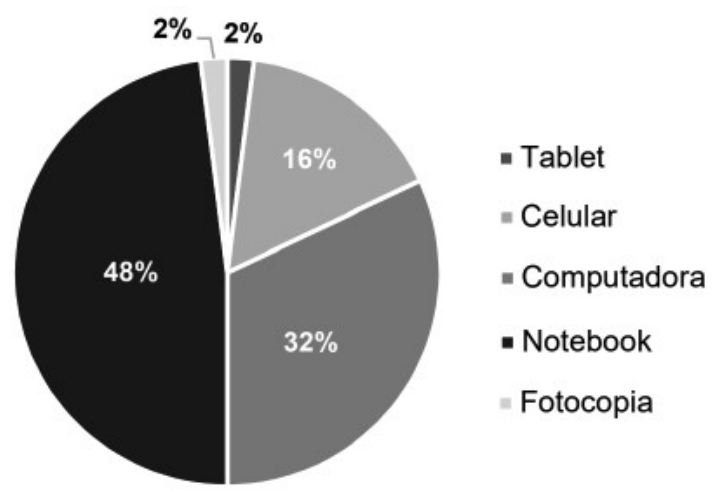

Figura 2. Recurso tecnológico más utilizado. (Fuente: elaboración propia).

Con respecto a los recursos empleados en la educación virtual, los estudiantes, en una pregunta que solicitaba valorar de 1 a 3 la importancia de distintos tipos de lenguaje, presentaron valoraciones muy parejas, pero que aun así señalan la preferencia de la imagen sobre el lenguaje verbal. Los videos e imágenes de Power Point lograron un promedio de 2,67 sobre 3; los textos escritos, 2,61; y los audios, 2,58.

Mayoritariamente, combinaron textos escritos con imágenes audiovisuales para terminar de comprender los temas desarrollados en las clases, que fueron reemplazadas parcialmente por videoconferencias al finalizar el cuatrimestre, cuando pudieron difundirse e instrumentarse en las aulas virtuales.

Para resolver problemas de comprensión lectora, el 39\% de los estudiantes compartió interpretaciones e inquietudes con sus compañeros, solo el 9\% pidió ayuda a los docentes, el 1\% tomó clases de apoyo y el 3\% recurrió a sus familiares o especialistas en las redes. El 48\% afirmó usar otra estrategia que pocos especificaron, pero que inferimos remite a estrategias tradicionales: lectura de resúmenes en las redes y ampliación de lecturas, relecturas y trabajo con el vocabulario.

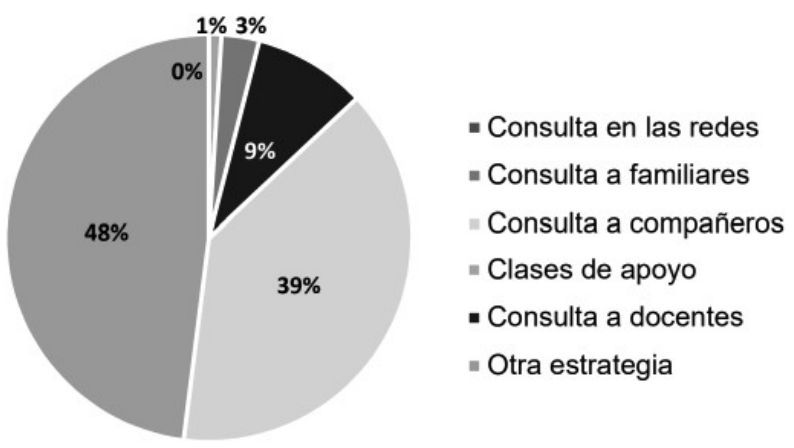

Figura 3. Estrategias de comprensión lectora. (Fuente: elaboración propia). 
Amelia María Zerillo, M. Fernanda Espelta, Nora A. Carra

La lectura académica en entornos virtuales. A propósito del aislamiento social preventivo y obligatorio (ASPO)

En cuanto a la calidad de la lectura mediada por los recursos tecnológicos, se observó que subsistieron allí los mismos problemas que en las prácticas tradicionales y hubo pocas mejoras, de las que hablaremos más adelante. Lo que surgió como evidente fue una jerarquización diferente de los conflictos habituales. En el caso de la lectura de escritos digitalizados, el 33\% de los estudiantes señaló como elementos preocupantes la extensión del texto (sobre todo en las materias más discursivas); el 20\%, la falta de atractivo del texto (en las materias menos discursivas, como las correspondientes a las carreras de Ingeniería y Arquitectura, Ciencias Económicas); el 19\%, la comprensión de las ideas; y el 10\%, el vocabulario. Un 18\% de los estudiantes, la mayoría correspondientes a los departamentos de Ciencias Jurídicas y Ciencias Económicas, manifestó no encontrar dificultades.

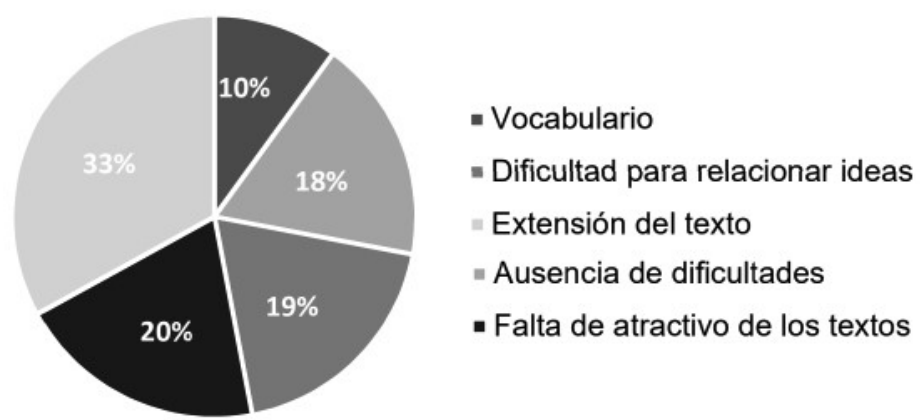

Figura 4. Problemas de lectura según los estudiantes. (Fuente: elaboración propia).

En la Figura 5 se puede observar de qué manera el problema de la extensión es común a todas las disciplinas, pero es menos significativo en la carrera de Ingeniería tal vez por la recurrencia a otro tipo de materiales de lectura: Power Point, gráficos, imágenes. En ese espacio se destacan el hecho de no tener problemas con la lectura, debido tal vez al bajo índice de lecturas que realizan, y la falta de atractivo de los textos. El problema de comprensión más específico, el vinculado con la comprensión de las ideas, aparece en segundo término en los departamentos de Humanidades y Ciencias de la Salud.

Respecto a la lectura de los estudiantes, los docentes en general reconocieron encontrar los mismos problemas de comprensión que en la educación presencial, y en esto no coinciden con los estudiantes. En estudios anteriores (Bidiña et al., 2014, 2016, 2017), en los que indagamos los nuevos modos de leer y escribir de los estudiantes, hemos constatado algunos de las más importantes: dificultades en la comprensión de las macroproposiciones incluidas en los textos, la realización de procesos inferenciales y la reposición de información histórica y contextual. En esta ocasión, el problema principal que señalaron los docentes fue la dificultad que tienen los estudiantes para 
Austral Comunicación

Volumen 10, número 2 (Diciembre de 2021): 351-373

ISSN (I) 2313-9129. ISSN (E) 2313-9137

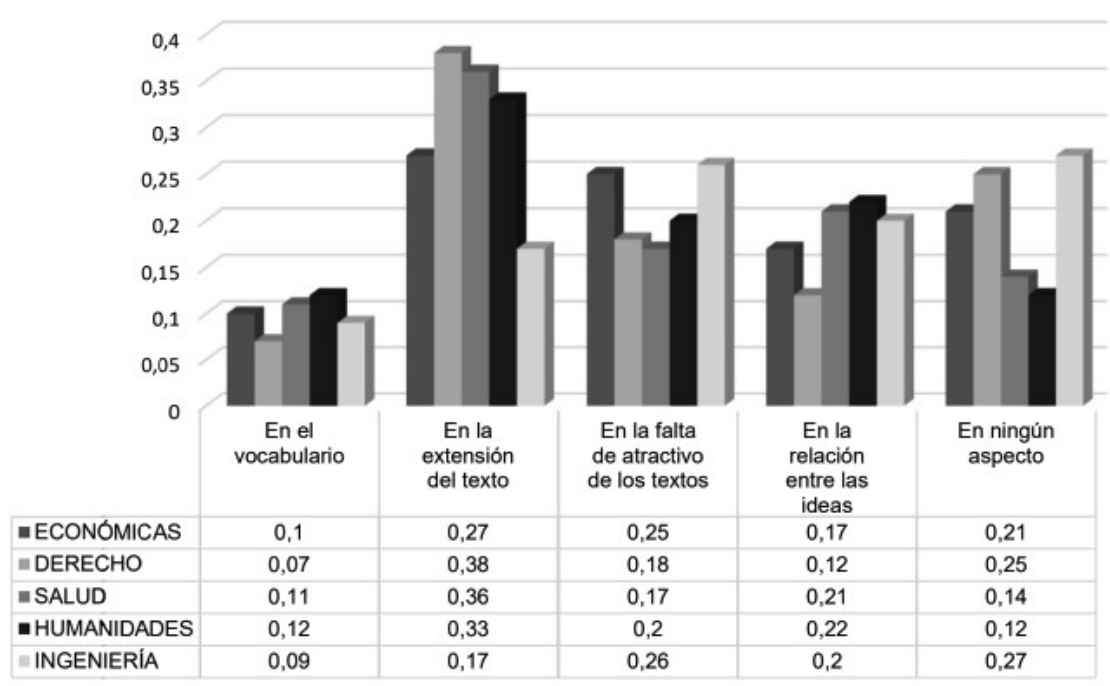

Figura 5. Problemas de lectura según los estudiantes en las distintas disciplinas. (Fuente: elaboración propia).

comprender consignas simples, relacionar ideas (macroproposiciones) y apropiarse del lenguaje de la disciplina. Así, sostienen que los alumnos, cuando se les pide que desarrollen, son muy breves y no explican los aspectos importantes, y cuando se les pide un concepto preciso, se extienden en otros temas, muchas veces sin tratar en profundidad aquel contenido solicitado. El grupo de profesores que respondieron la encuesta afirmó también que el 55,66\% de los textos de las clases y las actividades debieron ser reformulados para que los estudiantes los comprendieran. Dentro de este conjunto de docentes que reformularon sus textos, el $38 \%$ adujo que lo hizo porque los estudiantes no comprendían los conceptos y el vocabulario; el 14\%, porque los textos eran largos y complejos; el 9\% alegó que los textos tenían problemas de redacción y el 39\% invocó otras razones.

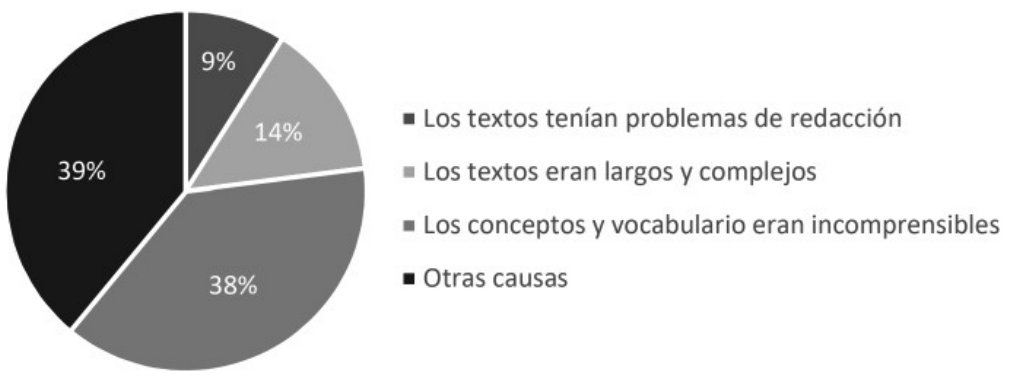

Figura 6. Reformulación de escritos. (Fuente: elaboración propia). 
Amelia María Zerillo, M. Fernanda Espelta, Nora A. Carra

La lectura académica en entornos virtuales. A propósito del aislamiento social preventivo y obligatorio (ASPO)

La excepción la presentaron los docentes de las materias analíticas o técnicas que, en el proceso pedagógico, recurrieron a textos breves o modalizados con imágenes porque entienden que las suyas son materias centradas en el discurso oral más que en el discurso escrito, aun cuando las encuestas revelan que reconocen problemas en la comprensión de textos sencillos, como el de las actividades a realizar, y en el lenguaje disciplinar. Para ellos, los alumnos no presentan graves problemas porque no trabajan con textos largos, sino con imágenes, y en las evaluaciones trabajan con ejercicios de opciones múltiples.

Por otra parte, fueron pocos los profesores que plantearon problemas que tuvieran que ver con la búsqueda de información en internet, la lectura de textos digitales y la comprensión de textos multimodales. Es decir, el eje problemático es la lectura y no el soporte.

Con respecto a las ventajas y desventajas que ofrecen los entornos virtuales para la lectura y el aprendizaje universitario, una de las preguntas abiertas reveló aspectos interesantes. Compartimos algunas opiniones ${ }^{4}$ que consideramos significativas, agrupadas por departamento.

\section{Humanidades y Ciencias Sociales}

- Hay muchos pros, como, por ejemplo, contenido audiovisual, libros en PDF, estar más cerca de compañeros y profes vía wasap, y los contras son pasar mucho tiempo sentado leyendo y frente a aparatos tecnológicos.

- A distancia, se suben muchos archivos PDF que no llaman la atención del alumno a simple vista, ya sea por el tamaño de la fuente o porque no es legible, por lo que cuesta más centrarse en leer la bibliografía ofrecida. Considero que se debe tener en cuenta que el alumno pasa horas sentado frente a una computadora y leer se hace tedioso con el pasar del tiempo, por lo que se debería brindar, además de los textos obligatorios, algo más visual para complementarlo y que la lectura sea más fácil, como por ejemplo un Power Point sobre el tema o un video explicativo introductorio, para que de esta forma, cuando el alumno lea el material, tenga una visión sobre qué trata el tema.

- La nueva modalidad modificó mi manera de estudiar, a veces al no tener una clase en vivo, no tengo una aproximación del tema, lo que lleva a costarme más el texto. El recurso de las consultas por foro y la respuesta de los docentes, que en su mayoría contestan enseguida, facilita poder seguir adelante con el tema sin esperar a volver a verlos.

4 Los comentarios fueron transcriptos con sus rasgos lingüísticos particulares. 
Austral Comunicación

Volumen 10, número 2 (Diciembre de 2021): 351-373 ISSN (I) 2313-9129. ISSN (E) 2313-9137

- La relación con la tecnología en este aspecto fue el mismo para mí, sin embargo, las clases online me dieron más tiempo para leer y escribir TP. Lo más importante es que podemos grabar las clases y esto me fue fundamental en varias ocasiones.

- Comencé a tomar apuntes con la computadora y siento que me será difícil volver al papel en la universidad cuando retornemos.

- Se me dificultó usar los recursos tecnológicos. Además, me resulta incómodo leer en la computadora. La computadora y el celular son muy necesarios, ya que me conecto vía ellos y obtengo información por internet.

- Al contar con todo en la computadora, y sin tener cerca una impresora o fotocopiadora, estoy cerca de 13 horas entre el trabajo y la facultad frente a la pantalla. Esto en parte perjudica la vista. Algunas clases deberían ser más interactivas, ya que el uso único del foro no permite que exista fluidez. Otro punto es que el profe esté disponible en las horas de cursada, ya que algunos no suelen responder.

- Absolutamente se modificó la relación de las tecnologías con los nuevos modos de leer y escribir. Previo al contexto mundial, el celular para mí era un elemento de ocio donde consideraría que un 30\% de mis responsabilidades pasaban por él (tanto en lo laboral como lo académico). Hoy en día, el celular se convirtió en un elemento esencial para completar mis responsabilidades en casi un $95 \%$. Antes lo utilizaba para mirar películas, revisar las redes sociales, para comunicarme con amigos o familiares y, de vez en cuando, era mi herramienta para realizar trabajos prácticos para la facultad o cumplir alguna que otra tarea laboral. La computadora siempre fue esencial en cualquier aspecto, pero ahora se sumó el celular y, de alguna manera, se desdibuja el uso que tenemos con él. Pasó de ser mi elemento de distracción a mi principal canal con el mundo exterior en todos los aspectos de mi vida. En la clase presencial se pierde mucho el intercambio entre compañeros, esos pequeños momentos sirven un montón para compartir ideas e incorporar nuevos conocimientos.

- Ya estaba familiarizada con la tecnología. En relación con las clases no presenciales vía internet, creo que algunos docentes deberían adoptar recursos prácticos para que los alumnos comprendan más rápido los contenidos de una materia, como presentaciones de Prezi o Power Point, y se les facilite estudiar textos extensos.

\section{Ciencias de la Salud}

- Considero que aprendí a usar formatos del celular que no tenía idea de cómo funcionaban, con lo cual considero una ventaja. Lo malo de las clases online 
Amelia María Zerillo, M. Fernanda Espelta, Nora A. Carra

La lectura académica en entornos virtuales. A propósito del aislamiento social preventivo y obligatorio (ASPO)

son los recursos que uno no puede tener. En mi caso particular, solo cuento con mi celular, no tengo impresora ni notebook, todas mis actividades las tengo que realizar a mano, tengo que leer desde el celular (que, de hecho, mi vista se lastimó respecto a esto) y, por ende, me lleva muchísimo más tiempo hacer algún TP, hacer algún dibujo, etc. Considero que esa es una gran desventaja para quienes nos encontramos en estas situaciones.

- La enseñanza virtual tiene muchos pros, como por ejemplo acceder a contenidos audiovisuales, libros en PDF, estar más cerca de lo compañeros y profes vía wasap. Entre los contras están: pasar mucho tiempo sentado leyendo y frente a aparatos; acceder a textos que no llaman la atención a simple vista, ya sea por el tamaño de la letra o porque no son legibles. Considero que se debe tener en cuenta que leer en estas condiciones se hace tedioso con el pasar del tiempo. Los textos deben complementarse con algo visual que haga fácil la lectura como un Power Point sobre el tema o un video explicativo introductorio para que antes de leer el alumno sepa de qué se trata.

- En este cuatrimestre cambió mucho mi relación con las tecnologías. Si bien siempre acudí a ellas, esta cursada online me obligó a pasar más tiempo frente a la computadora y, de esta forma, conocer herramientas que antes desconocía. Además de ello, al no sentirme cómoda leyendo grandes textos desde la pantalla, tuve que imprimir bibliografías completas, que generó un gasto extra. Los recursos que seguiré utilizando son la forma de comunicación con mis compañeros, como Teams, WhatsApp o redes, ya que es una buena forma de "reunirse" para trabajos grupales. Las clases no presenciales podrían mejorar, si todas las cátedras consideraran la importancia de explicar ciertos temas o responder preguntas y dudas de los alumnos en una comunicación fluida, como lo es en videollamadas como Teams.

\section{Derecho y Ciencias Políticas}

- En mi carrera, Ciencia Política, el material que se utiliza en las cursadas es casi en su totalidad online, es decir, consiste en PDF, por lo que no fue difícil acostumbrarme a estar constantemente con la computadora. Sí sentí el peso extra de las horas en clases por la plataforma Teams.

- Considero que la herramienta que se brindó fue efectiva en esta instancia de emergencia. Estoy de acuerdo con comenzar a implementar la metodología virtual, ya que es el nuevo paradigma y resuelve otros inconvenientes en donde el alumno presencialmente se ve afectado. Ayuda a la no distracción con compañeros y motiva al estudiante a poder estar con tranquilidad en la clase, ya que llegar a la universidad provoca dificultades muchas veces. La modalidad de TP 


\section{Austral @municación \\ Volumen 10, número 2 (Diciembre de 2021): 351-373 ISSN (I) 2313-9129. ISSN (E) 2313-9137}

sirve mucho para la práctica también. Los textos brindados virtualmente también hicieron ameno todo.

- Durante esta cursada, a nivel general lo que más me costó fue acostumbrarme a estar tantas horas frente a la computadora, la vista me empeoró al estudiar por videos y documentos en línea. Las estrategias y recursos que manejo son los mismos que tengo desde que comencé la carrera, y estar en esta modalidad online no me cambió. Con respecto a lo que debería mejorar es la ampliación o profundidad de los temas, el estar dando clases vía online no debe ser nada fácil para los docentes y lo que pude percibir en general es que no llegan a darle la profundidad necesaria a cada tema.

\section{Ciencias Económicas}

- Para empezar, estaría bueno que a los docentes les enseñen las nuevas herramientas y el potencial que tienen, algunos mostraron claro manejo de estas, pero a otros claramente les costó. Otro punto importante es que las clases se vuelven muy monótonas, estaría bueno que sean más interactivas y que se llame más a la acción a los alumnos, trabajos prácticos en línea, colaborativos, prestaciones semanales o quincenales, que les garanticen a los profesores que los alumnos están haciendo las cosas y siguiendo los temas.

- Desde el comienzo no tuve inconveniente, porque poseo muchas herramientas para llevar a cabo. Sin embargo, creo que es una dificultad para todos cuando en alguna materia los profesores no eligen dar al menos una clase por videoconferencia. Recursos que no abandonaría: poder consultar por MIieL con los profesores en cualquier momento.

\section{Ingeniería y Arquitectura}

- Considero que no han cambiado las relaciones de las tecnologías y estos nuevos métodos. Pero que supone un nivel de dificultad adicional para manejarse usando dispositivos electrónicos al leer un PDF. Algunas estrategias que he usado siempre fueron consultar videos en YouTube frente a un tema poco claro del profesor y/o libro y usar foros en otros idiomas.

- Se modificó positivamente en general porque había más material para consultar, en las clases presenciales a veces no hay un texto que acompañe la teoría, sino que depende mucho de lo que explique el profesor. No abandonaría imprimir el material, ya que leer de la pantalla es desgastante.

En estos testimonios, los estudiantes plantean distintos tipos de ventajas y desventajas que se pueden estructurar en tres ejes: el tiempo de estudio, la dificultad del 
Amelia María Zerillo, M. Fernanda Espelta, Nora A. Carra

La lectura académica en entornos virtuales. A propósito del aislamiento social preventivo y obligatorio (ASPO)

estudio virtual y la relación con los docentes. Respecto a la variable tiempo dedicado al estudio, los encuestados destacan que con la modalidad virtual es superior la cantidad de tiempo que necesitan para dedicarle a los estudios, y constituyen esta afirmación en una dificultad más allá del aspecto positivo que encuentran en el hecho de no tener que viajar hasta la Universidad.

Esta observación se presenta estrechamente relacionada con la dificultad de que los materiales de estudio se encuentren solo en forma virtual: la incomodidad es manifiesta, ya que no hay otra opción. Las distintas materias ofrecieron textos digitalizados, y quienes decidieron imprimir o acercarse a una fotocopiadora no estudiantil vieron en ello un gasto poco manejable. Finalmente, respecto a los docentes, los estudiantes señalaron la necesidad de que adopten estrategias adecuadas a la modalidad y reclamaron la asiduidad de las videoconferencias. De este modo, aparece la necesidad del contacto oral con los docentes como un modo de replicar las clases presenciales.

En síntesis, los resultados aquí presentados permiten organizar el estudio en dos bloques diferenciados. Por un lado, respecto a la variabilidad del uso y de los tipos de materiales didácticos, así como la percepción de los encuestados en relación con los entornos virtuales y el desafío de su uso. Todo ello presenta un amplio abanico de posibilidades que no se encuentran en estrecha relación con las disciplinas y podría interpretarse en relación con la cercanía/lejanía de los usuarios con las nuevas tecnologías.

Por otro lado, se empiezan a atomizar por disciplinas cuando se estudia la comprensión lectora, el uso de distintas modalidades para alcanzar la comprensión y los problemas de lectura. Los docentes, por su parte, también diferencian sus apreciaciones en relación con las disciplinas y las dificultades halladas en la comprensión de textos.

\section{Conclusiones}

Como docentes que enseñamos a leer y escribir desde una perspectiva discursiva, y como investigadoras dedicadas a estudiar estas prácticas en soporte papel y también en pantalla, los datos presentados nos permiten obtener algunas conclusiones respecto a los interrogantes planteados en la investigación y, en particular, sobre las prácticas letradas en las disciplinas. Estas conjeturas son de carácter provisorio y no son representativas de todas las experiencias académicas vividas en el contexto de pandemia. No todas las universidades son iguales. No todos los alumnos son iguales ni tuvieron $\mathrm{ni}$ tienen los mismos recursos para afrontar la educación a distancia.

Con respecto a los estudiantes, aun cuando numerosos estudios los consideran "nativos digitales", es decir, sujetos nacidos y educados en tiempos de las computadoras e internet, y por ello se presume que no ven en la tecnología un recurso extraño, ajeno a sus experiencias o amenazante, tenemos que afirmar que la gran mayoría no domina los recursos tecnológicos, no porque no los tengan -los datos personales de 


\section{Austral @municación \\ Volumen 10, número 2 (Diciembre de 2021): 351-373 ISSN (I) 2313-9129. ISSN (E) 2313-9137}

los estudiantes encuestados muestran que la mayoría los usaron durante este período de educación a distancia, ya que contaron con instrumentos propios o prestados y no desconocían su utilización básica-, sino porque no habían experimentado nunca la educación a distancia utilizando un entorno virtual. En efecto, la mayoría de nuestros estudiantes y los de muchas otras universidades no estaban habituados a la enseñanza virtual, tampoco a trabajos estáticos en la computadora. Una cosa es jugar o comunicarse en la web y otra es leer y estudiar frente a las pantallas tratando de profundizar en las ideas, subrayando y haciendo notas, acciones propias del mundo del papel que, también para la mayoría de los estudiantes, resultan agobiantes, pero queda claro por algunos comentarios que la actividad les generó un conflicto. El mundo del estudio y del trabajo se apropió de un espacio reservado para la evasión y el placer.

En investigaciones recientes (Albarello, 2019; García Canclini et al., 2015) se ha demostrado también que existen muchas clases de lectores y que un mismo lector es, a su vez, muchos lectores, ya que lee de modo diferente los diversos géneros discursivos. Para aquellos géneros que requieren más reflexión y más trabajo intelectual, la gran mayoría prefiere el papel o, si posee el recurso, una tablet que pueda usarse como el papel. La investigación realizada nos permitió confirmar estos datos y alejarnos de esa representación que vuelve a los docentes temerosos de las innovaciones y del uso de las tecnologías al considerar que los estudiantes saben mucho más y no pueden satisfacer sus expectativas. En numerosas ocasiones, pudimos constatar que los centros de estudiantes y las fotocopiadoras universitarias solicitaron los materiales porque los alumnos necesitaban imprimir las clases y los textos para leer, ya que carecían de impresoras y necesitaban leer en papel.

Este dato -junto a otros ya expuestos- nos permite esbozar algunas ideas respecto a la pervivencia de la cultura escrita. En este sentido, es necesario reconocer que el grado de presencia de textos escritos en el proceso de enseñanza-aprendizaje de nuestra institución, aun en tiempos de la videoconferencia y la virtualidad, fue alto. Esa modalidad siguió siendo la preferida por los docentes para el desarrollo de actividades más estáticas, aquellas que requieren de tiempo, distancia a los efectos de realizar una lectura atenta, reflexionar y apropiarse de los conceptos teóricos que caracterizan los textos disciplinares. En las interacciones entre docentes y estudiantes, y mayormente entre pares, la cultura oral fue dominante y la preferida. Las clases presenciales, de carácter expositivo-introductorias fueron las más apreciadas en esta instancia en la que algunos docentes delegaron todo en la palabra escrita.

No obstante, la presencia de la cultura escrita muestra ciertos índices de transformación. Es necesario señalar que el hecho de que en la mayoría de los casos los estudiantes prefirieran aprender mediante el uso de imágenes y videos, y no leer textos extensos, o leer, pero combinando con recursos visuales, insinúa, por un lado, que es- 
Amelia María Zerillo, M. Fernanda Espelta, Nora A. Carra

La lectura académica en entornos virtuales. A propósito del aislamiento social preventivo y obligatorio (ASPO)

tamos trabajando con lectores que leen y aprenden de otra manera y tienen otro tipo de representaciones de la discursividad; por el otro, el dato, si es cruzado con los resultados académicos logrados por aquellos estudiantes que prefieren la multimodalidad, es decir, la comunicación por distintos canales mediante los "íconotextos", ${ }^{5}$ este estudio advierte sobre la necesidad de formación en lectura de imágenes y lectura transmedia (Albarello, 2019) porque -hay que decirlo-, aun viendo imágenes y videos, aun leyendo en distintos soportes, los estudiantes no siempre alcanzaron la comprensión necesaria de los materiales bibliográficos o superaron las evaluaciones. Este problema se condice con la siguiente conclusión.

Con respecto al proceso de lectura en sí y a las dificultades que los estudiantes registraron al leer textos en pantalla, en casa, con la posibilidad de consultar en internet y contar en línea con el apoyo de sus compañeros y docentes, surge una llamativa diferencia entre la percepción de los docentes y los estudiantes. Mientras que para los estudiantes las complicaciones de la lectura parecen estar centradas en los aspectos externos de los textos, en la extensión y en el atractivo (aspectos que no parecen adecuarse a la lectura en pantalla), para los docentes los problemas tienen que ver con dificultades de comprensión muy antiguas y enquistadas, que vienen de hace muchos años y sobre los que los docentes entienden que poco pueden hacer y que, en algunos casos, no les incumbe.

Estas afirmaciones, que son las menos, pero que existen y son muy fuertes en las disciplinas alejadas del pensamiento humanístico, no solo dejan entrever la necesidad de formación docente en recursos didácticos digitales, sino que también ponen en suspenso los numerosos estudios que definen que la enseñanza de la lectura es un tema disciplinar, en tanto son los docentes de estas quienes dominan los rasgos internos de sus comunicaciones, conocen en profundidad su terminología y los secretos de los géneros discursivos que las distinguen y les dan un aire de familia a sus producciones escritas (Navarro, 2018; Padilla y Carlino, 2010). Cuando los profesores se quejan de que los estudiantes no entienden las consignas o de que realizaron una tarea que no se pidió, están afirmando que ese trabajo discursivo y metalingüístico que define en parte la tarea del docente no se está realizando con la intensidad suficiente como para mitigar esas dificultades comunicativas. Esto requiere de la puesta en funcionamiento

\footnotetext{
A fines del siglo XX, el desarrollo de las nuevas tecnologías de la comunicación provocó el surgimiento de nuevas prácticas, específicas, relacionadas con lo digital, y puso en el centro la característica multimodal de la comunicación (varios canales simultáneos). En efecto, el aumento constante de enunciados "escritos" que conllevan elementos icónicos introdujo el concepto de "íconotexto": se trata de producciones semióticas en las que imagen y palabra son indisolubles. De acuerdo con Maingueneau (2014), la dimensión icónica se observa en dos niveles: por un lado, los enunciados verbales que se incrustan en las imágenes o las imágenes que acompañan los textos, y, por otro, el ensamble de imágenes y enunciados verbales que trabajan como un todo. Así, páginas y sitios web, blogs, wikis, videojuegos, libros digitales combinan diferentes lenguajes o modos y, por lo tanto, se conciben en el marco de la multimodalidad.
} 
de las propias habilidades lingüísticas y discursivas, además de un acuerdo que, a su vez, demanda tiempos dedicados a la puesta en común de los principios operativos que posibilitan la interacción humana. De la misma manera, cuando los alumnos reclaman clases introductorias orales y la presencia docente antes de las presentaciones de los textos, están haciendo hincapié en otra de las funciones del lenguaje que abren el circuito de la comunicación pedagógica. Saludarse, presentarse e introducir un tema son requisitos fundamentales para que cualquier comunicación prospere. Mantener el canal abierto y accesible es otro. Activar los saberes previos de los lectores para ponerlos en juego al servicio de la lectura y plantearles objetivos de trabajo para que no se pierdan en el bosque de las palabras es también parte fundamental de la labor docente de toda institución de educación superior.

Por otra parte, las dificultades en la lectura de los estudiantes no estriban solamente en la falta de formación de estos o en la falta de lectura. Entendemos que los conflictos en la lectura, los vinculados a las exigencias de brevedad y atractivo que impiden la entrada a los textos, atentan contra la lectura total y el manejo de la bibliografía está en relación directa con una representación muy diferente de lo que para ellos es leer. Conjeturamos que las exigencias de extensión y atractivo no responden únicamente a la necesidad de tiempo, ese que deben pasar frente a la pantalla y que, justo es decirlo, se ha visto multiplicado en un año en el que la vida transcurrió entre pantallas. Proponemos también como otro factor coadyuvante al deseo de leer textos atractivos y breves el hábito de leer con rapidez y fruición en las redes sociales, con cuyos géneros están más familiarizados. Sugerimos que el desconocimiento de los géneros discursivos es un componente no menor en la naturaleza de las dificultades. Desconocimiento que se ve prohijado por algunas representaciones que existen y circulan en el interior de las propias disciplinas y que las encuestas docentes permiten testimoniar.

Según la encuesta, en algunas comunidades académicas, o más específicamente en algunas de sus tribus antes del ASPO, ya era más o menos habitual manejarse con documentos en PDF o Power Point (Derecho, Ciencias Económicas, Ingeniería). Para otros grupos, estos materiales eran desconocidos, como también lo eran las modalidades de interacción en un entorno virtual. De los datos presentados, resulta evidente que las prácticas letradas en las distintas disciplinas presentan notables diferencias. En aquellas menos discursivas, más analíticas y que tienden a trabajar con otros sistemas de representación simbólica, la lectura de documentos escritos no ocupa un lugar central, aunque los usen. Sin embargo, los testimonios dejan entrever problemas de lectura toda vez que, fuera de los ejercicios de selección múltiple o de completamiento de formularios, los docentes afirman que los estudiantes no resuelven los trabajos prácticos del modo en que ellos esperan o no entienden el vocabulario. 
Amelia María Zerillo, M. Fernanda Espelta, Nora A. Carra

La lectura académica en entornos virtuales. A propósito del aislamiento social preventivo y obligatorio (ASPO)

Las teorías cognitivas y la lingüística (Giroux, 1990) entienden que el alumno solo puede apropiarse del vocabulario disciplinar y desarrollar su aparato conceptual, ese que le permitiría relacionar ideas y entender el mundo, leyendo textos escritos, cumpliendo con las estrategias de apropiación diseñadas por los docentes de modo sistemático y fortaleciendo los hábitos de la cultura letrada en todas las materias, no solo en algunas. Los alumnos no aprehenden vocabulario ni desarrollan procesos de pensamiento solo exponiéndose a las transposiciones didácticas de gráficas, figuras o ejercicios de selección. Esto tiene que ver con una cultura disciplinar que lleva a entender que la lectura y la escritura en esas carreras no son necesarias. Hallamos que estas diferencias encontradas en las disciplinas son preocupantes en tanto pueden afectar los procesos académicos de los estudiantes y la constitución de lectores con espíritu crítico y reflexivo, como prevé el artículo 3 de la Ley 25573 de Educación Superior entre las funciones básicas de la institución universitaria.

Coincidimos con García Canclini $(2015)$ y Roger Chartier $(2005,2012)$ al afirmar la importancia del contexto en la formación de lectores. Todo lector nace en el seno de un grupo que condiciona su modo de leer y sus gustos, pero estos modos no son definitivos, cambian con los modos que tiene el sujeto de pensarse en el mundo y somos los docentes universitarios unos de los últimos profesionales que podemos ayudarlos a pensarse de un modo diferente, más seguro y competente.

No hay duda de que en ese proceso de formación del sujeto como lector las primeras lecturas tienen una impronta significativa y dejan un signo generacional. Los adultos nacidos antes de los 70 se iniciaron con los clásicos ilustrados y las enciclopedias. Los nacidos entre los 70 y los 90 llegaron a conocer la lectura interactiva y, muchas veces, llegaron al libro a través de la televisión, el cine y la cultura popular. Los nacidos después de los 90 conocen los libros junto a las computadoras y videojuegos, y entienden la pantalla y el papel como elementos complementarios y comunicados. Aprovechar esta situación puede ser útil para toda la comunidad. Como hemos visto entre el mundo del trabajo y los estudios, algunos alumnos pasaban más de doce horas frente a las pantallas. Mientras que para algunos la educación a distancia significó ahorro en viajes (en tiempo y dinero), para otros representó problemas visuales y corporales. Para muchos otros conllevó la posibilidad de leer más, de seguir sin interrupciones las exposiciones de los docentes y de concentrarse en el estudio. Asumir nuestra labor como formadores de los futuros lectores es nuestra obligación.

Para terminar, como docentes preocupadas por la formación de universitarios integrales, reflexivos, críticos y con conciencia social (Ley 24521; Unesco, 2018), encontramos preocupante que la formación intelectual del estudiante universitario como lector (y también como escritor, pero este es tema de un futuro artículo) no sea un objetivo compartido. En algunas disciplinas se lee y se escribe poco. Algunas de ellas 
Austral Comunicación

Volumen 10, número 2 (Diciembre de 2021): 351-373 ISSN (I) 2313-9129. ISSN (E) 2313-9137

son las que plantean con más frecuencia problemas de desarrollo conceptual, mal uso del vocabulario y desconocimiento de las normas. Es evidente que las distintas comunidades académicas trabajan con representaciones diferentes sobre la lectura y sobre el perfil del egresado universitario y, como sabemos, las representaciones tienen una gran incidencia en la construcción de la identidad de los miembros de un grupo y en el desarrollo de sus acciones (Jodelet, 1988).

\section{Referencias}

Albarello F. (2019). Lectura transmedia. Leer, escribir, conversar en el ecosistema de pantallas. Ampersand.

Bazerman, C., Little, J., Bethel, L., Chavkin, T., Fouquette, D. y Garufis, J. (2005). Reference Guide to Writing across the Curriculum. WAC Clearinghouse \& Parlor Press.

Berstein, B. (1965). A socio-linguistic approach to social learning. En Gould, J. (Ed.), Social Science Survey (pp.165-180). Penguin.

Bidiña, A., Luppi, L. y Smael, N. (2016). Lectura académica mediada por las TIC. Segundo Simposio Internacional de la Cátedra UNESCO para la lectura y la escritura. Universidad Nacional de Cuyo, Mendoza, 26 de octubre.

Bidiña, A., Zerillo, A., Gómez, S., Luppi, L., Miranda, M., Rocaro, S., Smael, N., Toledo, V. y Val, M. A. (2014). Enseñanza-aprendizaje en la universidad: nuevos modos de leer y escribir en los tiempos de la convergencia tecnológica. Universidad Nacional de La Matanza. http://repositoriocyt.unlam.edu.ar/handle/123456789/137.

Bidiña, A., Zerillo, A., Luppi, L., Miranda, M. N., Toledo, V. P., Smael, N. C., Gómez, S. y Val, M. A. (2017). Enseñanza-aprendizaje en la Universidad: nuevos modos de leer y escribir 2. Universidad Nacional de La Matanza. http://repositoriocyt.unlam.edu. ar/handle/123456789/752.

Bruner, J. (1984). Acción, pensamiento y lenguaje. Alianza.

Carlino, P. (2004). El proceso de escritura académica. Cuatro dificultades de la enseñanza universitaria. Educere, 8(26), 321-327.

Chartier, R. (21 de febrero de 2005). Jóvenes que no leen en un mundo inundado de textos. Página 12.

Chartier, R. (2012). Leer la lectura. En Actas del Seminario Internacional ¿Qué leer? ¿Cómo leer? Perspectivas sobre la lectura en la infancia (pp. 29-47). Unidad de Educación Parvularia, Ministerio de Educación, Gobierno de Chile.

De Sena, A. (2020). Y la brisa se convirtió en terremoto. El aislamiento por el Covid-19 en la Matanza. Revista Latinoamericana de Estudios sobre Cuerpo, Emociones y Sociedad, (31), 48-63. http://relaces.com.ar.

García Canclini, N., Gerber Bicecci, V., López Ojeda, A., Nivón Bolán, E., Pérez 
Amelia María Zerillo, M. Fernanda Espelta, Nora A. Carra

La lectura académica en entornos virtuales. A propósito del aislamiento social preventivo y obligatorio (ASPO)

Camacho, C., Pinochet Cobos, C. y Winocur Iparraguirre, R. (2015). Hacia una antropología de los lectores. Ediciones culturales Paidós/Fundación Telefónica/ Universidad Autónoma Metropolitana.

Giroux, H. (1990). Los profesores como intelectuales. Paidós.

Gómez, M. T. (2011). ¿Necesitamos una didáctica para la Lectura Académica en Pantalla? II Congreso en línea en Conocimiento Libre y Educación CLED, Universidad de los Andes, Bogotá, Colombia, 7 al 14 de octubre.

González García, J. (16 de octubre de 2013). Alfabetización multimodal: usos y posibilidades. Campo Abierto. Revista De Educación,32(1), 91-116. https:// mascvuex.unex.es/revistas/index.php/campoabierto/article/view/1387.

Halliday, M. (2004). Ideas sobre el lenguaje. En On language and linguistics (pp. 92115). https://cupdf.com/document/ideas-sobre-el-lenguaje-halliday.html.

Jewitt, C. (2009). Different approaches to multimodality. En Jewitt, C. (Ed.), The Routledge Handbook of Multimodal Analysis (pp. 28-39). Routledge.

Jewitt, C. y Kress, G. (Eds.). (2003). Multimodal literacy. Peter Lang.

Jodelet, D. (1986).La representación social: fenómenos, concepto y teoría.En Moscovici, S. (Ed.), Psicología social II (pp. 478-494). Paidós.

Lamarca Lapuente, M. J. (2009). Del papel a la pantalla. La lectura digital: soportes, dispositivos y formatos. http://artesadigital.blogspot.com/2009/01/la-escrituradigital-soportes.html

Lemke, J. (1997). Aprender a hablar ciencia. Lenguaje, aprendizaje y valores. Paidós.

Ley 24521 de Educación Superior, BO 07/08/1995.

http://servicios.infoleg.gob.ar/infolegInternet/anexos/25000-29999/25394/texact.htm.

Ley 25573 de Educación Superior, BO 30/04/2002. http://servicios.infoleg.gob.ar/ infolegInternet/verNorma.do?id=73892.

Maingueneau, D. (2014). Discours et analyse du discours: introduction. Armand Colin.

Martin, J. R. y Rose, D. (2012). Learning to Write, Reading to Lear. Genre, knowledge and pedagogy in the Sydney school. Equinox.

Navarro, F. (2018). Didáctica basada en géneros discursivos para la lectura, escritura y oralidad académicas. En Navarro, F. y Aparicio, G. (Eds.), Manual de lectura, escritura y oralidad académicas para ingresantes a la universidad (pp. 11- 21). Universidad Nacional de Quilmes. https:// www.researchgate.net/publication/323694320_Didactica_basada_ en_generos_discursivos_para_la_lectura_escritura_y_oralidad_disciplinares.

Padilla, C.y Carlino, P. (2010). Alfabetización académica e investigación acción: enseñar a elaborar ponencias en la clase universitaria. En Parodi, G. (Ed.), Alfabetización académica y profesional en el Siglo XXI: Leer y escribir desde las disciplinas (pp. 153182). Academia Chilena de la Lengua/Ariel. 
Austral Comunicación

Volumen 10, número 2 (Diciembre de 2021): 351-373

ISSN (I) 2313-9129. ISSN (E) 2313-9137

Parodi,G.(1999). Relaciones entre lectura y escritura: una perspectiva cognitiva discursiva. Bases teóricas y antecedentes empíricos. Universidad Católica de Valparaíso.

Piscitelli, A. (2010). Post-Gutenberg es Pre-Gutenberg. Quinientos años de textualidad son suficientes. http://www.filosofitis.com.ar/2010/05/24/post-gutenberg-es-pregutenberg-quinientos-anos-de-textualidad-son-suficientes/.

Prensky, M. (2010). Nativos e inmigrantes digitales. Distribuidora SEK. https:// marcprensky.com/writing/Prensky-NATIVOS\%20E\%20INMIGRANTES\%20 DIGITALES\%20(SEK).pdf.

Sapir, E. (1954). El lenguaje. Fondo de Cultura Económica.

Tolchinsky, L. (Coord.). (2013). La escritura académica a través de las disciplinas. Octaedro.

Unesco. (2018). Declaración Final de la III Conferencia Regional de Educación Superior en América Latina y el Caribe (CRES 2018). https://www.iesalc.unesco. org/2019/02/20/declaracion-final-de-la-iii-conferencia-regional-de-educacionsuperior-en-america-latina-y-el-caribe-cres-2018.

Vygotsky, L. (1978). Pensamiento y lenguaje. Paidós.

Whorf, B. L. (1956). Language, Thought and Reality. The M.I.T. Press. 